\title{
OPTIMIZATION OF GMAW WELDING PARAMETERS FOR MICRO-ALLOYED A572 GR.50 STEEL
}

\author{
MANISH DEO*, S. P. TEWARI \& G. S. MAHOBIA \\ Department of Mechanical Engineering, Indian Institute of Technology (Banaras Hindu University), Varanasi, \\ Uttar Pradesh, India
}

\begin{abstract}
Gas metal arc welding (GMAW) is a simple process due to which it is mostly automated, and hence once welding parameters are established, it is possible to produce long and repeatable welds. Mechanical/material properties around heat affected zone (HAZ) are greatly influenced by the welding parameters. In the present study, emphasis was to observe the weld bead variations, morphology and weld microstructure with respect to different current and travel speed combinations under the same heat input. The results revealed that combination of parameters had significant effect on microstructural feature of welded structure and hence weld strength. Through Taguchi approach optimum parameters were established for the welding and the performance corresponding to this were observed in terms of microstructure, hardness and strength.

KEYWORDS: GMAW, Shielding Gas Mixture $\left(82 \% A r+18 \mathrm{CO}_{2}\right)$, Microstructure \& Tensile Strength
\end{abstract}

Received: Jun 05, 2020; Accepted: Jun 25, 2020; Published: Jul 29, 2020; Paper Id.: IJMPERDJUN2020522

\section{INTRODUCTION}

High-strength low-alloy (HSLA) steels, or micro alloyed steels, are designed to provide better mechanical properties and/or greater resistance to atmospheric corrosion. Specific mechanical properties/chemical properties can be achieved by micro alloying[1] ASTM A572 gr 50 HSLA is a columbium-vanadium steel grade having wide applications in offshore structures, shipbuilding, bridges, oil/gas vessels, agricultural and construction machines etc[2].Depending upon the applications and requirements, welding process can provide desired attachment between two surfaces, although the weld strength does get affected by the direction of rolling of the base metal and other metallurgical properties. Welding process can easily accommodate a base plate thickness of 0.5 to $15 \mathrm{~mm}[3]$.For fabrication of large and complex structures the weld joint strength is also affected by direction of rolling and metallurgical properties[4].Gas metal arc welding provides the benefit of long, uniform and defect free joints through parametric control and automation. In GMAW, arc generated between consumable electrode and work-piece provides sufficient heat energy for change in properties of weld bead(WB) as well as of un-melted base metal i.e. HAZ. Heating cycles in welding leads to variation in weld joint strength, thus it becomes essential to analyze the effect of microstructural changes on strength of the welded joint. For a favorable microstructural feature and optimum joint strength,emphasis is given to the welding process parameters in order to achieve the optimum width of HAZ.Although, it is reported that [5, 6]cold cracks that are often observed in HAZ of HSLA steels are related to microalloying elements and thermal cycle experienced by the material during welding. Low level of carbon equivalent (CE) for A572 gr 50 steels are more weldable and lesser susceptible to cold cracking[2]. The susceptibility for cracking can be reduced by low cooling rate, while at high cooling rates, the structures like martensite are the prerequisite for creating the cold cracks leading to lower strengths. Although ferrite and perlite are not sensitive to 
cold cracks, HAZ would have superior toughness if structures like martensite and lower bainite are present while quenched structures like martensite is the prerequisite for engendering cold cracks[7].The welding parameters greatly affect the heat input during welding and hence the microstructural feature and consequently the hardness and strength. Microstructural features are affected by heat input first and then by cooling rate. Higher heat input leads to generation of coarser grain structure[8].Moreover, welding speed and shielding gas regulation influence the cooling rate. Higher welding speed may result in under fill or humping bead due less heat input, considered as geometrical weld defect which affect the quality of production $[9,10]$.However, cracks and ripple cavities are formed at low speeds (due to high heat input) while center line cavities and cracked versions arise due to high speeds. Also, lower welding speeds lead to increase in percentage of intergranular ferrite(IGF).Shielding gas composition and its flow characteristic significantly affect weld and HAZ area. As weld bead surface, heat extraction, and ultimately the mechanical properties are affected by gas flow rate and maximum gas coverage and protection of bead is ensured by sufficient shielding[11, 12].Among frequently chosen blends of shielding gases (like $\mathrm{Ar}+\mathrm{He}, \mathrm{Ar}+\mathrm{CO}_{2}, \mathrm{Ar}+\mathrm{CO}_{2}+\mathrm{He}+\mathrm{O}_{2}$ etc.), blend of $\mathrm{CO}_{2}$ with $\mathrm{Ar}$ being an economical choice (than $\mathrm{He}$ ) is generally chosen which leads to better arc stability, higher penetration, low spatter and better weld quality[13].Studies from various studies reported so far, it can be observed that emphasis has been on the weld metal configuration and properties due to weld cycle. Blending of Argon and $\mathrm{CO}_{2}$ can be further investigated for sound weld and gas flow rate effect on bead shape. HAZ in HSLA steels having asoft zone can be deleterious for the welded joint and is of great concern[14]. Methods like PWHT can be fruitful in the austenite region to eliminate soft HAZ zone in HSLA but cannot be used for lager structures. External cooling methods, like copper backing and argon purging can be a useful tool[15]. The size and number of defects like cracks, center cavities, cracked center cavities, ripple cavities, undercut and humps increased markedly with the welding current. Studies suggests that all welding parameters must be considered to estimate weld geometry with certainty[16].The effect of parameters like Current (I), weld speed(s) and gas flow rate(f) has been chosen for investigation in the present study. Current and weld speed dictate not only the overall heat imparted in the weld metal and HAZ but, also, predicts the shape, size and metallography of WB and HAZ and finally the strength.

Optimizing the result and choosing the best possible way to get superior properties are key point in the present investigation. HSLA steels designed for better metallurgical and mechanical strength becomes more sensitive to heat input and the welding parameters due to which acceptable range becomes very narrow. Increase in current promotes percentage of IGF consequently toughness decreases with wider CGHAZ generated during slowly cooled weld joints[17]. Shielding gas also influences the total heat retained in the welded area as it protects oxidation and removes the heat and ultimately affects the metallurgy of the weld joint. Optimum process parameters control the size and metallurgical properties of WB and HAZ.

\section{MATERIALS AND METHODS}

AISI A572 gr 50 hot rolled plates with dimension $200 \mathrm{~mm} \times 50 \mathrm{~mm} \times 5 \mathrm{~mm}$ were machined on milling machine to get the $60^{\circ} \mathrm{V}$ grove joint configurations, as shown in Figure 1(a).IS6419(AWS A5.18:ER70S-6) Consumable electrode with diameter $1.2 \mathrm{~mm}$ has been used for experimentation. As it is known to provide minimum spatter and stable arc during MIG/GMAW under optimum welding conditions[18]. It is an acceptable interpretation that, slightly over alloyed filler metal with equal or slightly higher tensile strength with respect to base metal should be used[19]. The chemical composition of base metal and filler material has been tabulated in Table 1. The work pieces to be welded were cleaned with ethanol and then butt-welded by automatic GMAW machine (ESAB RC-AUTO-K400). The set-up used for the welding has been shown in figure 1(b).

Table 1: Chemical Composition wt\% 


\begin{tabular}{|l|c|c|c|c|c|c|c|c|c|c|c|c|}
\hline \multicolumn{1}{|c|}{ Grade } & C & Si & Mn & Mo & Cr & P & S & Ni & V & Cd & Co & Fe \\
\hline A572 gr. 50 & 0.08 & 0.4 & 0.35 & 0.02 & 0.02 & 0.02 & 0.01 & 0.015 & 0.001 & 0.001 & 0.002 & \multirow{2}{*}{ Balance } \\
\hline Filler wire ER70S-6 & 0.19 & 0.98 & 1.61 & -- & -- & 0.025 & 0.025 & -- & -- & --- & --- & \\
\hline
\end{tabular}

a)

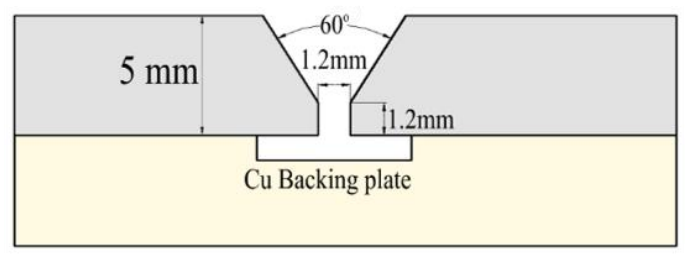

\section{b)}

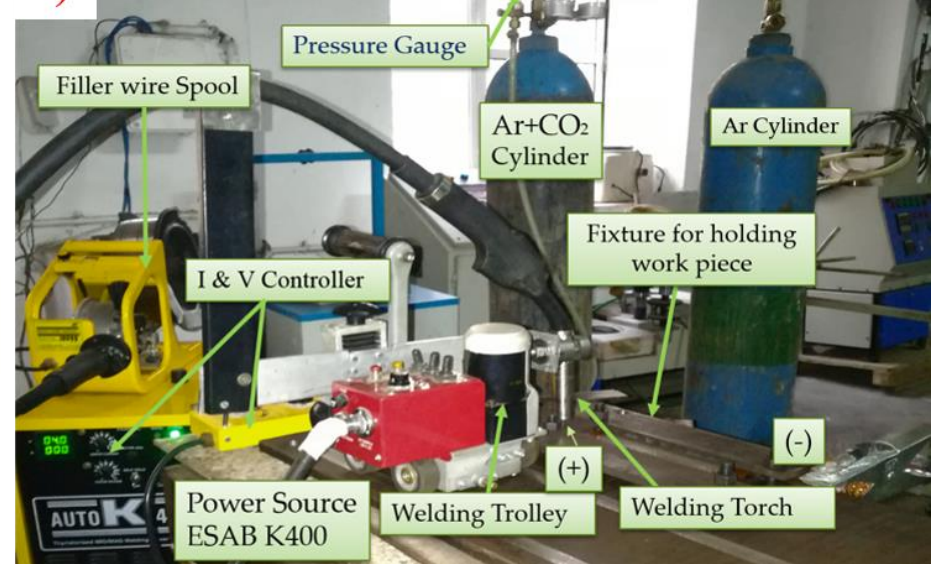

Figure 1: A) Schematic Diagram of Welded Joint Configuration, B) Actual Diagram of Welding Setup Used.

GMAW welding torch mounted on a variable speed (up to $10 \mathrm{~mm} / \mathrm{sec}$ ) MAXIMIG 251 trolley was used for experimentation. Fabricated workpieces were tacked with root gap of $1.2 \mathrm{~mm}$ and rigidly mounted on $\mathrm{Cu}$ backing plate using fixture for fabrication. A $10^{\circ}$ torch angle and work piece to contact tube distance of $15 \mathrm{~mm}$ was set for fabrication. Shielding gas composition of $82 \% \mathrm{Ar}-18 \% \mathrm{CO}_{2}$ in Direct Current Electrode Positive mode has been used for experimentation. As gas mix is known to provide stable arc with deeper penetration at lower current values because $\mathrm{CO}_{2}$ has lower ionization potential ultimately/consequently it increases the total heat imparted to the work piece. With increase in $\mathrm{CO}_{2}$ there has been decrease in UTS from 2 to $4 \%$ and least effect on YS[20].

\subsection{Optimization by Taguchi Analysis}

In this study, concept of Design of Experiment (DOE) has been used through Minitab 17 software to optimize the welding parameters for A572 gr. 50 steel. Taguchi's robust design approach was used to generate the L9 orthogonal matrix. 3factors and 3level has been chosen on the basis of preliminary results of GMAW welding as shown in table 2 and table 3 . Total 9 experiments were conducted based on input parameters and corresponding levels to find the influence of welding variables of current (I), gas flow rate(f) and welding speed(s) on tensile strength, hardness and microstructures.

Taguchi's method has been proved to be a popular tool for gaining the benefits of quality and cost effectiveness by reduced experimentation cost for researchers[14]. Various steps involved in Taguchi method are Process parameters identification, defining the levels, selection of experimental matrix, evaluation of signal to noise ratio, analysis of variance (ANOVA), determination of optimal level for factors followed by confirmation of optimal process parameter[21]. Workpieces were also analyzed for quality of weld in terms of weld bead appearance as performance measure.

Table 2: L9 Array, Welding Variables for Experimentation Factors

\begin{tabular}{|c|c|c|}
\hline Level 1 & Level 2 & Level 3 \\
\hline
\end{tabular}




\begin{tabular}{|l|c|c|c|}
\hline Current (I) in Amp & 100 & 135 & 170 \\
\hline Gas flow rate (f) in L/min & 10 & 14 & 18 \\
\hline Welding Speed (S) in mm/sec & 1.25 & 2.50 & 3.75 \\
\hline
\end{tabular}

Table 3: L9 Matrix Results for HI, YS and UTS

\begin{tabular}{|c|c|c|c|c|c|c|}
\hline $\begin{array}{c}\text { Sample } \\
\text { No. }\end{array}$ & $\begin{array}{c}\text { Current } \\
(\text { Amp })\end{array}$ & $\begin{array}{c}\text { Gas Flow Rate } \\
(\mathbf{L} / \mathbf{m i n})\end{array}$ & $\begin{array}{c}\text { Welding Speed } \\
(\mathbf{m m} / \mathbf{s e c})\end{array}$ & $\begin{array}{c}\text { Heat Input } \\
(\mathbf{k J} / \mathbf{m m})\end{array}$ & $\begin{array}{c}\text { Yield } \\
\text { Strength } \\
(\mathbf{M P a})\end{array}$ & $\begin{array}{c}\text { UTS } \\
(\mathbf{M P a})\end{array}$ \\
\hline S1 & 100 & 10 & 1.25 & 1.1424 & 330 & 390 \\
\hline S2 & 100 & 14 & 2.5 & 0.5376 & 329 & 389 \\
\hline S3 & 100 & 18 & 3.75 & 0.3584 & 321 & 405 \\
\hline S4 & 135 & 10 & 2.5 & 0.77112 & 334 & 395 \\
\hline S5 & 135 & 14 & 3.75 & 0.57456 & 328 & 385 \\
\hline S6 & 135 & 18 & 1.25 & 1.54224 & 320 & 390 \\
\hline S7 & 170 & 10 & 3.75 & 0.68544 & 313 & 399 \\
\hline S8 & 170 & 14 & 1.25 & 1.82784 & 320 & 435 \\
\hline S9 & 170 & 18 & 2.5 & 0.91392 & 325 & 410 \\
\hline
\end{tabular}

\subsection{Evaluation of Signal to Noise(S/N) Ratio}

YS, UTS and heat input were chosen as response variables to evaluate the effect of various parameters. Therefor "higher the better" for YS and UTS were selected for analysis. Also lower the better criteria was selected for Heat input.

After experimentation with Minitab17 using Taguchi method UTS S/N ratio has been tabulated in table 4.Further to find out the effects and contribution of Yield Strength(YS) Versus Current, Gas Flow Rate, and Weld Speed for criteria of

Table 4: Taguchi Analysis for UTS S/N Ratio

\begin{tabular}{|c|c|c|c|}
\hline Level & Welding Current & Gas flow rate & Welding speed \\
\hline 1 & 51.92 & 51.92 & 52.14 \\
\hline 2 & 51.82 & 52.09 & 52.00 \\
\hline 3 & 52.35 & 52.08 & 51.96 \\
\hline Delta & 0.53 & 0.17 & 0.18 \\
\hline Rank & 1 & 3 & 2 \\
\hline
\end{tabular}

"Larger the better" and its response for means has been tabulated in table 5For effect and contribution of UTS Verses Current, gas flow rate, weld speed once again "Larger the better" criteria has been used and its response for means has been tabulated in table 6 . Through the analysis it was deduced that current is the most influential parameter followed by weld speed and gas flow rate. Main effects plot for data means has been an indicative for finding the optimum parameter.

Table 5: Taguchi Analysis: Yield Strength Versus Current, Gas Flow Rate and Weld Speed

\begin{tabular}{|c|c|c|c|c|c|c|}
\hline \multicolumn{2}{|c|}{ Response for Signal to Noise Ratios "Larger is Better" } & \multicolumn{3}{c|}{ Response for Means } \\
\hline Level & $\begin{array}{c}\text { Welding } \\
\text { Current }\end{array}$ & $\begin{array}{c}\text { Gas Flow } \\
\text { Rate }\end{array}$ & $\begin{array}{c}\text { Welding } \\
\text { Speed }\end{array}$ & $\begin{array}{c}\text { Welding } \\
\text { Current }\end{array}$ & $\begin{array}{c}\text { Gas Flow } \\
\text { Rate }\end{array}$ & $\begin{array}{c}\text { Welding } \\
\text { Speed }\end{array}$ \\
\hline 1 & 50.32 & 50.25 & 50.37 & 328.0 & 325.7 & 330.3 \\
\hline 2 & 50.11 & 50.36 & 50.40 & 320.3 & 330.0 & 331.3 \\
\hline 3 & 50.57 & 50.38 & 50.23 & 338.0 & 330.7 & 324.7 \\
\hline Delta & 0.46 & 0.13 & 0.17 & 17.7 & 5.0 & 6.0 \\
\hline Rank & 1 & 3 & 2 & 1 & 3 & 2 \\
\hline
\end{tabular}


Table 6: Taguchi Analysis: UTS Versus Current, Gas Flow Rate, Weld Speed

\begin{tabular}{|c|c|c|c|c|c|c|}
\hline \multicolumn{2}{|c|}{ Response for Signal to Noise Ratios "Larger is Better" } & \multicolumn{4}{c|}{ Response for Means } \\
\hline Level & $\begin{array}{c}\text { Welding } \\
\text { Current }\end{array}$ & $\begin{array}{c}\text { Gas Flow } \\
\text { Rate }\end{array}$ & $\begin{array}{c}\text { Welding } \\
\text { Speed }\end{array}$ & $\begin{array}{c}\text { Welding } \\
\text { Current }\end{array}$ & $\begin{array}{c}\text { Gas Flow } \\
\text { Rate }\end{array}$ & $\begin{array}{c}\text { Welding } \\
\text { Speed }\end{array}$ \\
\hline 1 & 51.92 & 51.92 & 52.14 & 394.7 & 394.7 & 405.0 \\
\hline 2 & 51.82 & 52.09 & 52.00 & 390.0 & 403.0 & 398.0 \\
\hline 3 & 52.35 & 52.08 & 51.96 & 414.7 & 401.7 & 396.3 \\
\hline Delta & 0.53 & 0.17 & 0.18 & 24.7 & 8.3 & 8.7 \\
\hline Rank & 1 & 3 & 2 & 1 & 3 & 2 \\
\hline
\end{tabular}

\subsection{Analysis of Variance (ANOVA) For S/N Ratios}

After analyzing through ANOVA (table 7) it was observed that various parameters contributed in response variables. Current contributed the most (53\%) followed by welding speed $(6.6 \%)$ and gas flow rate $(6.25 \%)$. Optimum process parameter analyzed through main effect plot as shown in figure 2(a) was $170 \mathrm{Amp}$ current, $14 \mathrm{~L} / \mathrm{min}$ gas flow rate and $1.25 \mathrm{~mm} / \mathrm{sec}$ welding speed i.e. sample no. S8. Effects can also be seen through the surface plots drawn in figure 2(b) and 2(c). The Taguchi's results can be verified through the microstructural changes and hardness patterns which would be discussed later.

Table 7: Analysis of Variance for UTS, using Adjusted SS for Tests

\begin{tabular}{|c|c|c|c|c|c|c|c|}
\hline Source & DF & Seq SS & Adj SS & Adj MS & $\mathbf{F}$ & $\mathbf{P}$ & \% Age Contribution \\
\hline Current & 2 & 1030.2 & 1030.2 & 515.1 & 1.60 & 0.385 & 53.61 \\
\hline Gas flow rate & 2 & 120.2 & 120.2 & 60.1 & 0.19 & 0.843 & 6.25 \\
\hline Welding speed & 2 & 126.9 & 126.9 & 63.4 & 0.20 & 0.835 & 6.60 \\
\hline Error & 2 & 644.2 & 644.2 & 322.1 & & & 33.55 \\
\hline Total & 8 & 1921.6 & & & & & \\
\hline
\end{tabular}
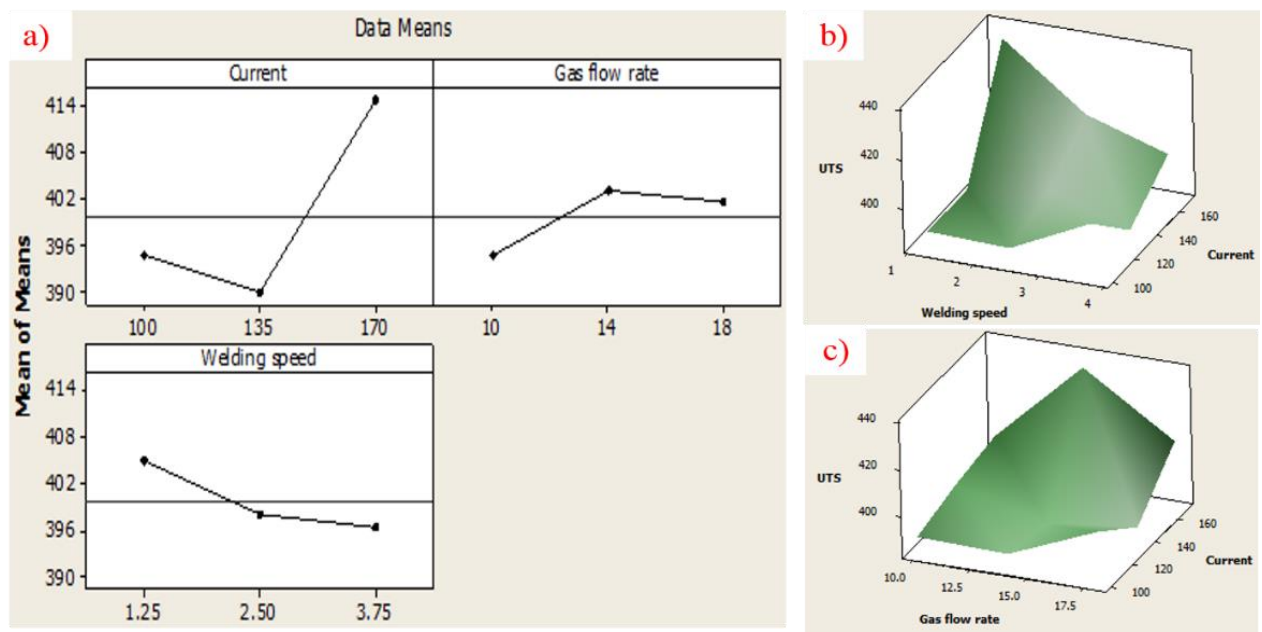

Figure 2: a) Main Effects Plot for Data Means, Surface Plot of UTS Versus b) Current and Weld Speed c) Current and Gas Flow Rate.

Samples for microstructure characterization, tensile and hardness tests were prepared according to ASTM standard. For microstructure, samples were metallographically polished i.e. grinding (SiC emery papers upto 2500 grit size), mechanical polishing followed by chemical etching with $2 \%$ Nital $\left(\mathrm{HNO}_{3}\right)$ solution for 20 s. Optical microscopy was conducted by Leitz Metallux-3) at different magnification (100X and 500X).For Vickers micro hardness test the indentations were taken at $2.5 \mathrm{~mm}$ below the top surface along transverse section at anterval of $0.5 \mathrm{~mm}$ at a load of $100 \mathrm{~g}$ and $10 \mathrm{sec}$ dwell time. Dog-bone shaped specimens were prepared for tensile test according to ASTM E8M-04 Standard using CNC 
machine followed by grinding upto800grit size emery paper to remove the irregularities occurred during welding[22]. Tensile test was conducted on a computer controlled Instron (4206) under ambient condition at a cross head speed of $1 \mathrm{~mm} / \mathrm{min}$. The fractured surfaces were observed under SEM for fractography.

\section{RESULTS AND DISCUSSIONS}

\subsection{Heat Input Analysis}

Heat input in welding plays an important role in formation of different phases/microstructure in WB, FZ and HAZ. It has been calculated using following equation and tabulated in table 3[23]:

$$
\text { Heat Input }(\mathrm{Kj} / \mathrm{mm})=0.84 \frac{\text { Voltage }(\mathrm{V}) \times \text { Current }(\mathrm{Amps})}{1000 \mathrm{x} \text { Travel speed }(\mathrm{mm} / \mathrm{s})}
$$

Calculated HI values for Samples S1 to S9 prepared under different conditions has been tabulated in table 3, which varied from a maximum of $1.74 \mathrm{~kJ} / \mathrm{mm}$ (in sample no. S8) to a minimum of $0.34 \mathrm{~kJ} / \mathrm{mm}$ (in sample no.S3).It can be observed that current is the most influencing parameter with 53.6\% contribution (from Taguchi analysis).It governs the total heat imparted in the welding as it is directly proportional to $\mathrm{HI}$ and increased electrode melting rate for higher heat input[17]. The $\mathrm{HI}$ has large effect on the soft zone width in $\mathrm{HAZ}$ as well as control the maximum temperature attained causing variable hardness in the WB and HAZ. It is evident from the hardness graph that, there lies a soft zone governed by cooling rate in WB and HAZ[24].It is evident from the tensile test and hardness test results tabulated in table 3 and 11. SamplesS2, S3, S5 and $\mathrm{S} 7$ with low heat input (up to $0.65 \mathrm{~kJ} / \mathrm{mm}$ )and medium gas flow rate of $12 \mathrm{l} / \mathrm{mincor}$ responds to higher cooling rate which leads to the formation of harder phases and increases strength and the microhardness of the HAZ and WB. Also, for sample no S1, S4, S6, S9 and S8 with high welding heat input (max.1.74kJ/mm)due to constitutional super coiling, there is sufficient time for grain growth in coarse grain heat affected zone(CGHAZ) which also caused the disappearance of martensite gradually with the formation of bainitic structure. Increment in width of HAZ can be easily observed for high HI from micrograph of HAZ as it forces slow cooling and microstructural change for larger area in HAZ. The wider HAZ width is undesirable as it increases the non-uniform structured area, in welded joints and hence the critical failure zone. For various weld parameters/heat inputs HSLA steel base metal experienced different thermal cycles, and different microstructures were formed in HAZ[16]. When the welding heat input was around $0.5 \mathrm{~kJ} / \mathrm{s}$, the cooling time was low and thus fast cooling rate easily produced brittle and hard phases in HAZ.

\subsection{Macrostructure Analysis}

Each nital etched sample revealed a distinctly visible HAZ along arc surrounding weldment. Welding parameters for sample no S1, S3, S8 and S9 produced a perfect bead shape and good penetration with depth to width ratio not exceeding 2:1 which will avoid solidification cracking[25]. Top and side view of welded joint with different welding parameters are tabulated in table 8.These samples depict perfect elliptical bead top with respect to other parameters. Bead width varied from $5.41 \mathrm{~mm}$ (for S2) to $8.76 \mathrm{~mm}$ (for S4) at the top. Sample S2 has the highest reinforcement followed by S8 and S9 which further lowered to the base plate level in S5 plate for $3.75 \mathrm{~mm}$ speed and medium gas flow rate. No undercuts or other defects were found on any sample within the weld parameters selected, but sample S5 and S7 has beads almost collinear with welded plate. 
Table 8: Macrostructure, Bead width, Fusion Area and Bead Appearance

\begin{tabular}{|c|c|c|c|c|c|c|c|c|c|}
\hline $\begin{array}{c}\text { Sample } \\
\text { No } \\
\end{array}$ & S1 & S2 & S3 & S4 & S5 & S6 & S7 & S8 & S9 \\
\hline \begin{tabular}{|l|} 
Cross \\
Sectional \\
View \\
\end{tabular} & & & & & & & & & \\
\hline $\begin{array}{l}\text { Bead top } \\
\text { View }\end{array}$ & is & & 12 & & 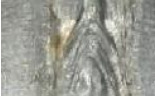 & AI & 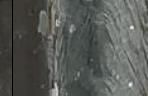 & (5) & \\
\hline $\begin{array}{l}\text { Bead Width } \\
(\mathrm{mm})\end{array}$ & 8.76 & 7.28 & 6.99 & 8.55 & 7.56 & 5.41 & 6.67 & 8.12 & 7.78 \\
\hline $\begin{array}{l}\text { Bead } \\
\text { Appearance }\end{array}$ & Good & Good & Very Good & OK & Not Good & Not Good & Good & Very Good & Very Good \\
\hline
\end{tabular}

High heat input gave wider bead at lower speeds. Appearance of bead shown fully protected bead with luxurious appearance without any spatter spots or defects on either side of weld also providing benefit of no further finishing requirement for the weld. At various heat inputs excellent welds can be performed by selecting proper combinations as conditions for S3, S7, S8 and S9 which has good tensile strength as revealed from tensile test results.

\subsection{Microstructural Analysis}

The effect of different parameters on microstructural variation was studied through optical micrographsas shown in figure 3 at resolution 500X. Ferrite and a small amount perlite can be observed from the micrograph. According to the Taguchi analysis the optimum parameters were for sample no. S8. BM, WB and HAZ microstructures has been shown in figure 4. S8 depicting the microstructural features containing ferrite, pearlite, and acicular ferrite with narrow CGHAZ with respect to other parameters.

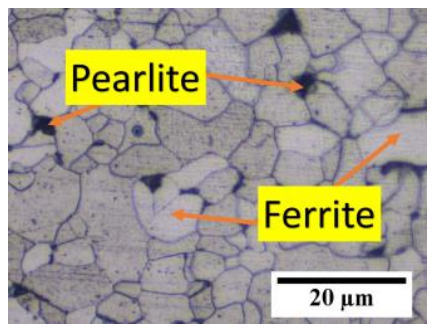

Figure 3: Base Metal A572 gr. 50.

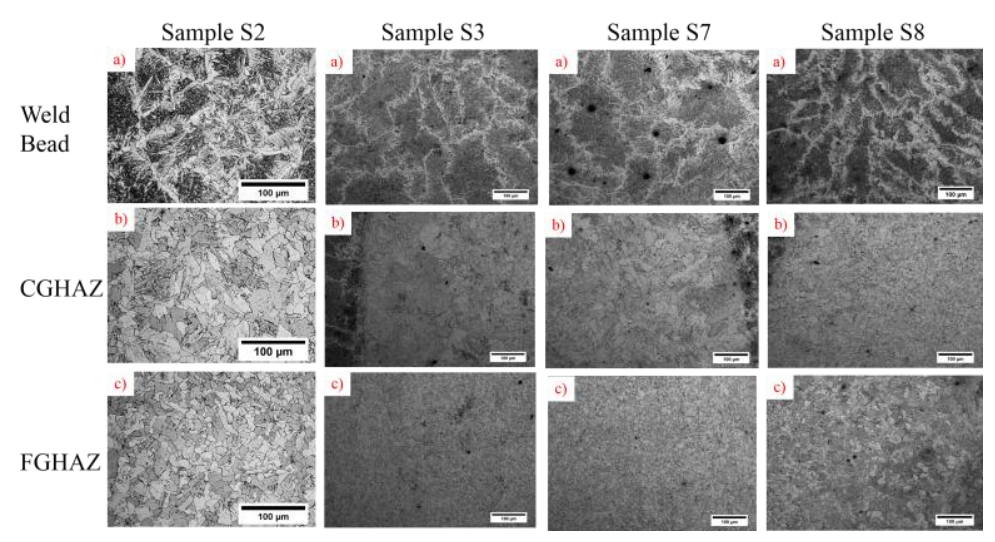

Figure 4: Optical Micrograph of S2, S3, S7 and S8 with a) Weld Bead,

b) CGHAZ, c) FGHAZ, d) Base Material.

The effect of different heat inputs with different preheat temperatures (PT) on microstructure in CGHAZ has been 
studied, and the optical microstructures are shown in Gas flow rate has significant effect on the cooling rate in WM and HAZ region. A lower shielding gas flow rate for sample 3 would result in a fast weld metal cooling rate which favours the production of a finer microstructure. As from micrograph of different samples from sample no 4, 5 and 6 with increasing gas flow rate. Similarly from micrograph of different samples for increasing heat input from S3 $(5.02 \mathrm{~kJ} / \mathrm{cm}), \mathrm{S} 7(6.34 \mathrm{~kJ} / \mathrm{cm})$, $\mathrm{S} 6(16.06 \mathrm{~kJ} / \mathrm{cm})$ and $\mathrm{S} 8(16.47 \mathrm{~kJ} / \mathrm{cm})$ the average prior-austenite grain size in CGHAZ increases gradually. The microstructures consist of martensite (dark spots), a number of M-A constituents, and some grain boundary ferrite (GBF) distributed along the prior-austenite grain boundaries and bainitic structure in WM. With increase in heat input the grain size in CGHAZ has increased due to constitutional super cooling effect as well as martensite has disappeared from CGHAZ at higher heat inputs as for sample no.S7and S8.

HSLA steels derive strength by the formation, presence and dispersion of fine carbide particles in the microstructure. Presence of carbon provides solid solution strengthening while concurrently enabling in a noticeable increase in hardenability arising from the formation, presence and dispersion of alloy carbide particles in the microstructure. Lesser martensite was found in the CGHAZ possibly due to high $\mathrm{HI}$ and low carbon content of the parent steel. The WM zone microstructure ferrite, acicular ferrite (AF), polygonal ferrite (BF) and Widmanstatten ferrite and upper and lower bainite (WSPF)[26]. Similar structures have been found in AISI 1010 steel welds.

\subsection{Microhardness Analysis}

The hardness of base material was observed to be150VHN. The hardness values of different zones of weld joints of sample S8with parameters170Amp(I), $18 \mathrm{l} / \mathrm{min}(\mathrm{f})$ and $2.5 \mathrm{~mm} / \mathrm{sec}(\mathrm{s})$ speed is depicted in figure 5(a).Micro hardness for various other samples showed a variation in hardness from base to center of weld bead and has been tabulated in table 9 . A sudden dip in hardness just after the fuzion line in the CGHAZ was also observed which we speculate due to larger grain size. It was found that hardness of all zones of weld joints of weld pool and HAZ enhances with the increase of weld speed and current due to faster solidification of weld pool at higher speed and relatively faster cooling rate at higher welding speed because of lower temperature gradient.

Table 9: Hardness Distribution in Different Zones of Welded Specimen

\begin{tabular}{|c|c|c|c|c|c|c|c|c|c|c|}
\hline Sample No & BM & S1 & S2 & S3 & S4 & S5 & S6 & S7 & S8 & S9 \\
\hline $\mathrm{We}$ & \multirow{3}{*}{152} & 268 & 265 & 265 & 278 & 275 & 274 & 277 & 265 & 272 \\
\hline $\mathrm{CGH}$ & & 215 & 270 & 278 & 199 & 203 & 180 & 200 & 245 & 202 \\
\hline FGHAZ & & 250 & 268 & 290 & 263 & 256 & 249 & 265 & 255 & 254 \\
\hline
\end{tabular}
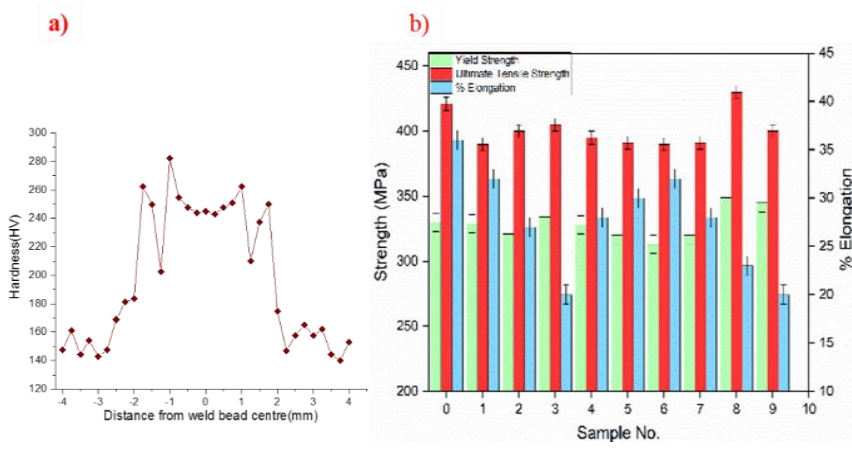

c)

Figure 5: a) Hardness Distribution for S8, b) Tensile Test Results According to L9 Matrix,

\subsection{Tensile Test Analysis}

c) SEM Fractograph of S8. 
Generally, the weld metal is kept comparatively stronger, and the joint properties are controlled by weld metal chemical composition and microstructure. In uniaxial tensile tests, all specimens fractured away from weld bead i.e. either in base metal or HAZ. Various results of tensile test has been tabulated in figure 5(b). Yield strength (YS) and ultimate tensile strength (UTS) of base plate were observed to be 318MPa and 390MPa respectively (point 0). Maximum strength was observed for sample S8 with parameters of 170amp current, 181/min gas flow rate and $2.5 \mathrm{~mm} / \mathrm{sec}$ weld speed and is in agreement with the results obtained from Taguchi analysis. With increase in current there has been decrease in yield strength and has similar effect with increase in heat input due to decrease in cooling rate. Gas flow rate influenced the grain size in WB and HAZ causing grain size at low gas flow rate and higher UTS and YS. Scanning electron micrograph of fractrograph of specimen S8 is shown in figure5(c). It can be observed that it resembles the typical ductile mode fracture with dimples and plastic flow (white lines). $\mathrm{Nb}, \mathrm{Ti}, \mathrm{V}$, etc. being a strong carbide/nitride forming elements, contributing to strength by precipitation hardening as they have limited solubility in ferrite and austenite[27]. It may be the reason that the yield strengths of most of the welds increased compared to the parent metal. The percentage elongation of yield point is attributed to the interaction of solute atoms and moving dislocations[28].

\section{CONCLUSIONS}

The following conclusions may be derived from the experimental investigations:

- From the present investigation, significant variations in bead morphology and weld microstructure can be seen which occur under identical heat input but with different current and travel speed combinations.

- Optimum parameters for higher strength, low heat input and uniformity in grain size in HAZ was achieved with sample no S8. So 170Amp of current, weld speed of $1.25 \mathrm{~mm} / \mathrm{sec}$ and gas flow rate of 141/min is recommended for welding the specimens.

- With increase in current from 100Amp to 170Amp there is increase in hardness of HAZ and decrease in ultimate tensile strength was observed and hence with weld at center of the specimen the work piece gets fractured from the HAZ.

- Welding heat input (welding current and speed) affects microstructure of weld metal. As heat input increases, the width of HAZ area also increases and decreases due to increased melting rate. Significant grain coarsening was found in the HAZ of all the joints.

\section{REFERENCES}

1. J. Fernández, et al.,(2007), Effect of microalloying elements on the austenitic grain growth in a low carbon HSLA steel, Materials Letters 61(11-12) 2389-2392.

2. J. Davis, (2001),Alloying, Understanding the Basics (ASM International, 2001).

3. T. Kasuya, et al.,(1995), Determination of necessary preheat temperature to avoid cold cracking under varying ambient temperature, ISIJ international 35(10) 1183-1189.

4. El-Shennawy, M., et al. "Heat treatment effect on micro-alloyed low carbon steel with different Boron content." International Journal of Mechanical Engineering (IJME), 5 (4), 920 (2016).

5. S. Gowda, et al.,(2015), The microstructure, tensile response and fracture behavior of a high-performance structural steel: influence of orientation, Emerging Materials Research 4(2) 255-264. 
6. B. Beidokhti, et al.,(2009), Effects of alloying elements and microstructure on the susceptibility of the welded HSLA steel to hydrogen-induced cracking and sulfide stress cracking, Materials Science and Engineering: A 507(1-2) 167-173.

7. S.G. Lee,et al.,(2017), Effects of Ni and Mn addition on critical crack tip opening displacement (CTOD) of weld-simulated heataffected zones of three high-strength low-alloy (HSLA) steels, Materials Science and Engineering: A 697 55-65.

8. J.L. Zhouet al.,(2011), Effect of Heat Input on Microstructure and Properties in Heat Affected Zone of ASTM A572 GR. 65 Steel, Advanced Materials Research, Trans Tech Publ,, pp. 553-557.

9. W.S.H.W. Mudaet al.,(2015), Effect of welding heat input on microstructure and mechanical properties at coarse grain heat affected zone of ABS grade A steel, ARPN Journal of Engineering and Applied Sciences 10(20) 9487-9495.

10. El-Shennawy, M., et al. "Effect of boron content on metallurgical and mechanical characteristics of low carbon steel." Int. Jl. Mech. Engg.(IJME), 5 (2), 114 (2016).

11. N.U. Khanet al.,(2019), To study mechanical properties and microstructures of MIG welded high strength low alloy steel, Materials Today: Proceedings 18 2550-2555.

12. L. Wanget al.,(2016), Backward flowing molten metal in weld pool and its influence on humping bead in high-speed GMAW, Journal of Materials Processing Technology 237 342-350.

13. Yadav, Devendra, and Abhishek Gaikwad. "Comparison and testing of tensile strength for low \& medium carbon steel." International Journal of Mechanical Engineering (IJME), 4 (5), 18 (2015).

14. B.K. Khamariet al.,(2019), Effect of welding parameters on mechanical and microstructural properties of GMAW and SMAW mild steel joints, Ironmaking \& Steelmaking, 1-8.

15. B. Mvola, et al., (2017), Effects of shielding gas control: welded joint properties in GMAW process optimization, The International Journal of Advanced Manufacturing Technology 88(9-12) 2369-2387.

16. B. John, et al., (2016), The role of shielding gas on mechanical, metallurgical and corrosion properties of corten steel welded joints of Railway Coaches using GMAW, Advances in Science and Technology Research Journal 10(32).

17. Joseph, O. O., et al. "Material performance investigation on the failure of an aircraft (ABT-18) Nose Wheel Strut." International Journal of Industrial Engineering \& Technology (IJIET) 2.3 (2012): 1-6.

18. S. Mukhopadhyay et al.,(2006), Effect of shielding gas mixture on gas metal arc welding of HSLA steel using solid and fluxcored wires, The International Journal of Advanced Manufacturing Technology 29(3-4) 262-268.

19. F. Hochhauser, et al.,(2012), N. Enzinger, Influence of the soft zone on the strength of welded modern HSLA steels, Welding in the World 56(5-6) 77-85.

20. T. Mohandaset al.,(1999), Heat-affected zone softening in high-strength low-alloy steels, Journal of Materials Processing Technology 88(1-3) 284-294.

21. M. Gucwaet al.,(2014), The effect of heat input on the geometric properties of welded joints, Archives of Foundry Engineering 14.

22. M. Shome, (2007), Effect of heat-input on austenite grain size in the heat-affected zone of HSLA-100 steel, Materials Science and Engineering: A 445 454-460.

23. U. Ersoy et al.,(2008), Observation of arc start instability and spatter generation in GMAW, Welding Journal-New York- 87(2) 51. 
24. R.S. Funderburk,(1999), Selecting filler metals: matching strength criteria, Welding Innovation 16(2) 10-12.

25. D. C Montgomery,(1997) Montgomery Design and Analysis of Experiments, John Wiley.

26. G. Magudeeswaran et al.,(2014),Optimization of process parameters of the activated tungsten inert gas welding for aspect ratio of UNS S32205 duplex stainless steel welds, Defence technology 10(3) 251-260.

27. A. International, ASTM E8/E8M-09 Standard Test Methods for Tension Testing of Metallic Materials, ASTM, 2011.

28. M. Singla,(2010), Parametric optimization of gas metal arc welding processes by using factorial design approach, Journal of Minerals and Materials Characterization and Engineering 9(04) 353.

29. J. Wang et al.,(2012), Effect of welding process on the microstructure and properties of dissimilar weld joints between low alloy steel and duplex stainless steel, International Journal of Minerals, Metallurgy, and Materials 19(6) 518-524.

30. A. Momeni et al.,(2011), Hot deformation behavior of austenite in HSLA-100 microalloyed steel, Materials Science and Engineering: A 528(4-5) 2158-2163.

31. J. Janget al.,(1987), Inclusion effects on submerged-arc weld microstructure, Journal of materials science 22(2) 689-700.

32. I. Brown, (2006), The role of microsegregation in centreline cold cracking of high strength low alloy steel weldments, Scripta materialia 54(3) 489-492.

\section{AUTHORS PROFILE}

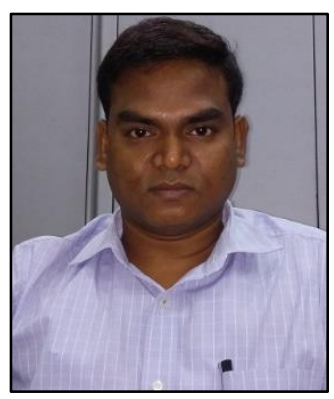

Manish Deo is currently pursuing Ph.D. in Mechanical Engineering from the Indian Institute of Technology (BHU) Varanasi, India. He completed B.Tech in Mechanical Engineering from Uttar Pradesh Technical University, Lucknow (UP), India in 2007. After completing B.Tech, he joined IIT (BHU) Varanasi, India for M.Tech (Production Engineering) in year 2009 under the supervision of Prof. S. P. Tewari. After that he joined IIT (BHU) Varanasi for Ph.D. (Mechanical Engineering) in year 2015, under the supervision of Prof. S. P. Tewari. He is currently working in the field of "Behavior of Heat Affected Zone Under Different Welding Conditions in GMAW”. His research interests include metallurgical and mechanical behavior of fabricated materials.

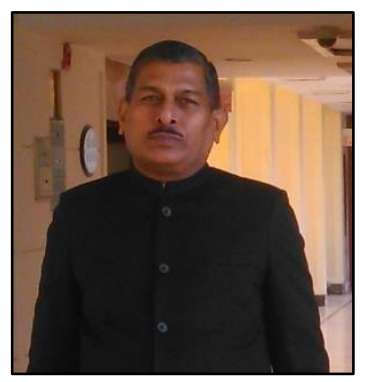

Prof. S.P. Tewari is working in the Department of Mechanical Engineering, IIT (BHU), Varanasi since 14 Feb 
1981. He has completed his B.E. and M.E. in Mechanical Engineering from Motilal Nehru Regional Engineering College, Allahabad. He has completed his Ph.D. in 1998 from IIT (BHU), Varanasi-221005. He has authored five books in the area of Manufacturing Science, Workshop Technology and Advanced Welding Technology. He has published more than 33 papers in International Journals and 22 papers in National Journals and Conferences.He has supervised more than 30 master's theses and $3 \mathrm{Ph}$.D. Theses.He was Chairman Senate Library Committee, Main Library, IIT(BHU) for two consecutive years. He was also Vice President of Mechanical Engineering Society for two consecutive years. He was DUGC convener and DFAC member for two years.He has delivered several invited talks. He was Principal Investigator/Investigator of different research projects sponsored by UGC, AICTE, DAE and ONGC. He is editor and reviewer of national and international journals. He is Fellow Member of Institutions of Engineers (India).

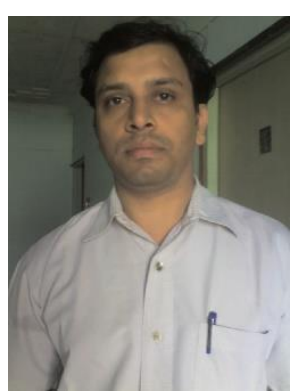

Dr. GS Mahobia is graduated (Met. Engg.)in 2001 from GEC-Raipur (now NIT-Raipur); post graduated (Met. Engg.) in 2003 from IT-BHU (Now IIT-BHU) Varanasi and obtained doctoral degree ( Met. Engg) in 2013 from Department of Metallurgical Engineering, IIT-BHU, Varanasi. He joined M/s Jindal Steel and Power Limited (JSPL) Raigarh (CG) in 2003 as an engineer in DRI plant. He has obtained experience in operating 300MT rotary kiln for sponge iron production. Dr. Mahobia joined M/s Larsen and Toubro Ltd.-Heavy Engineering Division (HED) - Surat (Gujarat) in 2004 as a PGET and rose to the level of Assistant Manager in Welding Engineering and Metallurgy. He had contributed significantly in the area of welding development, heat treatment and failure analysis up to the period of 2007 . He has been awarded 1st Rank in 'Manthan' (afocussed improvement system), 2005 and a certificate of merit for the implementation of GMAW process of welding for the first time in L\&T-Surat. He has also qualified as a Six Sigma Green Belt in 2006 by Qimpro College-USA. Dr. Mahobia, joined Metallurgical Engineering Department (IT-BHU) as Lecturer on 17th September 2007 and promoted to Associate Professor in 16th October 2015. 